\title{
Pediatric fear-avoidance model of chronic pain: Foundation, application and future directions
}

\author{
Gordon JG Asmundson PhD ${ }^{1}$, Melanie Noel MSc${ }^{2}$, Mark Petter MA², Holly A Parkerson BA(Hons) ${ }^{1}$
}

GJG Asmundson, M Noel, M Petter, HA Parkerson. Pediatric fearavoidance model of chronic pain: Foundation, application and future directions. Pain Res Manage 2012;17(6):397-405.

The fear-avoidance model of chronic musculoskeletal pain has become an increasingly popular conceptualization of the processes and mechanisms through which acute pain can become chronic. Despite rapidly growing interest and research regarding the influence of fear-avoidance constructs on pain-related disability in children and adolescents, there have been no amendments to the model to account for unique aspects of pediatric chronic pain. A comprehensive understanding of the role of fear-avoidance in pediatric chronic pain necessitates understanding of both child/adolescent and parent factors implicated in its development and maintenance. The primary purpose of the present article is to propose an empirically-based pediatric fear-avoidance model of chronic pain that accounts for both child/adolescent and parent factors as well as their potential interactive effects. To accomplish this goal, the present article will define important fear-avoidance constructs, provide a summary of the general fear-avoidance model and review the growing empirical literature regarding the role of fear-avoidance constructs in pediatric chronic pain. Assessment and treatment options for children with chronic pain will also be described in the context of the proposed pediatric fear-avoidance model of chronic pain. Finally, avenues for future investigation will be proposed.

Key Words: Adolescents; Anxiety; Children; Fear-avoidance; Pain; Parentchild; Pediatric

$\mathrm{T}$ he fear-avoidance model has become an increasingly popular conceptualization of the processes and mechanisms through which an acute pain experience can become chronic. The model itself has its roots in early behavioural and cognitive work, has been amended several times, and has led to the development and evaluation of conceptually related treatment options. In recent years, there have also been important advances in the evaluation and application of the fearavoidance model within the context of pediatric pain. The present review has several purposes. First, we will define several constructs that are central to the fear-avoidance model. Second, we will summarize the fear-avoidance model and its various iterations. Third, we will review the growing empirical literature focusing on applications of fear-avoidance constructs in understanding persistent pain in pediatric samples. Fourth, we will propose an empirically-based pediatric fearavoidance model of chronic pain that may improve its heuristic value in the pediatric milieu. Fifth, we will describe assessment and treatment options for children and adolescents with various types of chronic pain stemming from the model and provide a narrative review of effectiveness and efficacy studies. Finally, we will identify avenues for future investigation.

\section{IMPORTANT CONSTRUCTS}

Pain

Acute pain (ie, pain with a sudden onset, often stemming from some form of illness process or tissue injury) is adaptive in that it signals potential for actual damage and motivates action to limit damage and promote recovery. Acute pain experiences subside with physical

\section{Un modèle d'appréhension-évitement des douleurs chroniques en pédiatrie : les assises, l'application et les futures orientations}

\begin{abstract}
Le modèle d'appréhension-évitement des douleurs musculosquelettiques chroniques gagne en popularité pour conceptualiser les processus et mécanismes par lesquels la douleur aiguë peut devenir chronique. Malgré un intérêt de plus en plus marqué et des recherches sur l'influence du concept d'appréhension-évitement sur les invalidités liées à la douleur chez les enfants et les adolescents, le modèle n'a pas été modifié pour tenir compte des aspects uniques de la douleur chronique en pédiatrie. Pour bien comprendre le rôle de l'appréhension-évitement en cas de douleur chronique en pédiatrie, il faut comprendre à la fois les facteurs liés à l'enfant ou à l'adolescent et aux parents, qui contribuent à son apparition et à son maintien. Le présent article vise avant tout à présenter un modèle empirique d'appréhension-évitement de la douleur chronique en pédiatrie, qui tient compte à la fois des facteurs liés à l'enfant ou à l'adolescent et aux parents et de leurs interactions potentielles. Pour réaliser cet objectif, il contient une définition des principaux concepts d'appréhension-évitement, un résumé du modèle général d'appréhension-évitement et une revue des publications empiriques croissantes sur le rôle des concepts d'appréhensionévitement en cas de douleur chronique en pédiatrie. Il contient également une évaluation des enfants souffrant de douleur chronique ainsi que les possibilités thérapeutiques à leur endroit, selon le modèle proposé d'appréhension-évitement de la douleur chronique en pédiatrie. Il se termine par des suggestions de futures recherches.
\end{abstract}

recovery, but for some, acute pain transitions through a complex interaction of biological, psychological and social processes to become chronic (1). Chronic pain is typically defined as pain persisting longer than three months (2). Available data indicate that approximately $27 \%$ of community-dwelling children and adolescents report current chronic pain (3), which is comparable with estimates in adult community samples (4). Unlike acute pain, chronic pain is not adaptive; indeed, in both children/adolescents and adults it is associated with considerable emotional distress, increased risk of developing psychiatric disorders, impaired social and educational/occupational functioning and increased use of medical services (5-11). Although chronic pain is often associated with negative outcomes, it is important to note that some adults $(12,13)$ and children (14) with chronic pain cope effectively and adapt in a manner that enables them to maintain their quality of life. Our focus in the present review is on chronic pain that has negative outcomes for the children experiencing it.

\section{Fear and anxiety}

Fear and anxiety are related but distinct constructs (15). Fear is a response to the perception of an immediate and often concrete threat that motivates defensive behaviour (eg, escape). Anxiety, on the other hand, is a response to the anticipation of threat that motivates preventive behaviour (eg, avoidance). Fear and anxiety are related in that they comprise multiple response modalities (ie, physiological, cognitive, behavioural) and mutually reinforce one another. Fear can facilitate cognitions regarding the likelihood that immediate threats will recur, leading to anticipatory anxiety regarding recurrence. As a result,

${ }^{1}$ Department of Psychology, University of Regina, Regina, Saskatchewan; ${ }^{2}$ Department of Psychology, Dalhousie University, Halifax, Nova Scotia Correspondence: Dr Gordon JG Asmundson, Department of Psychology, University of Regina, 3737 Wascana Parkway, Regina, Saskatchewan S4S OA2. Telephone 306-347-2415, fax 306-337-3275, e-mail gordon.asmundson@uregina.ca. 
this increases the likelihood that threats will be detected on recurrence and that fear will be experienced. Other stimuli associated with a fear-provoking threat may also become threat cues and, thereby, provoke anxiety.

In the context of the fear-avoidance literature of chronic pain, the terms (and associated constructs of) fear and anxiety are often used interchangeably (16). Because distinguishing between fear of pain and pain-related anxiety is supported empirically $(17,18)$ and is potentially useful both theoretically and clinically, we draw the distinction in the review and model proposal that follows. This distinction parallels the general distinction between fear and anxiety, wherein fear of pain is conceptualized as a response to an immediate pain-related threat (eg, initiating a painful activity), and pain-related anxiety is a response that occurs in anticipation of pain-related threat (eg, expecting an activity to be painful). It is noteworthy that while the focus of fear or anxiety in the context of persistent pain is often on specific objects or experiences, such as the onset of a headache, the focus can also extend to perceptions of self-worth and identity formation (19).

\section{FEAR-AVOIDANCE MODEL}

The contemporary fear-avoidance model of chronic musculoskeletal pain stems from two independent reviews published in close temporal proximity at the turn of the millennium $(20,21)$. These reviews, while differing somewhat in focus, provided a historical account and critique of a growing body of literature supporting the role of fear and anxiety as factors responsible, at least in part, for the maintenance of disabling musculoskeletal pain experienced by some people. The fearavoidance model of chronic musculoskeletal pain can be summarized as follows. Pain resulting from an injury is perceived and appraised with respect to its significance and meaning. Depending on the nature of the appraisal, the person may respond in an adaptive or potentially maladaptive manner. For most people, the pain is judged to be undesirable and unpleasant, but not catastrophic; accordingly, most people engage in appropriate behavioural restriction followed by graduated increases in activity until healing has occurred. For a significant minority of people, a catastrophic meaning (ie, 'This pain means I'm never going to be able to do the things I like doing') is placed on the pain experience. Catastrophizing - influenced by predispositional and current psychological factors - results in fear of pain and pain-related anxiety. For some people with chronic pain, this anxiety spirals into a vicious and self-perpetuating cycle that may promote and maintain avoidance, functional disability, depression, and additional pain and catastrophizing.

The reviews of Asmundson et al (20) and Vlaeyen and Linton (21) and, in particular, the model proposed by Vlaeyen and Linton, have stimulated a considerable amount of research; indeed, a search of Web of Knowledge using the Web of Science Index (conducted November 16,2011 ) yielded more than 1000 collective citations to these works. Similarly, a search of MEDLINE with full text (EBSCOhost) using the search terms pain AND fear-avoidance OR fear of pain OR painrelated anxiety limited to abstracts in academic journals published between January 2000 and December 2011 (conducted November 16,2011 ) yielded 1470 relevant articles. As illustrated in more recent reviews (22-25), the results of this research provide general support for the postulates of the fear-avoidance model. The model was initially intended to describe individuals with idiopathic chronic musculoskeletal pain; however, there is growing evidence that it is applicable to other pain conditions including headache (26), fibromyalgia (27) and severe burns (28). Researchers and theorists also continue to refine the model, with proposed modifications reflecting elaboration of associated mechanisms $(16,29)$ and evidence that putative predispositional traits, such as anxiety sensitivity, are associated with the development and maintenance of fear of pain $(30,31)$. In recent years, there has also been considerable emerging evidence that the fear-avoidance model is, at least in part, of value in understanding and treating a variety of pediatric pain conditions.

\section{STATE OF THE SCIENCE IN PEDIATRIC PAIN}

While pain intensity and severity of illness/injury are associated with functional disability in children and adolescents with chronic pain $(32,33)$, the extent of disability experienced by a minority of young people is not adequately explained by pain intensity or frequency alone (14). Consequently, there has been growing interest in identifying potentially modifiable factors that influence pain-related disability in pediatric populations. A Delphi poll of international researchers and clinicians in the field (34) identified several child-specific psychological responses (eg, catastrophizing) and behaviours (eg, avoidance), each consistent with the fear-avoidance model, as being among the most important factors in the development of pediatric chronic pain and pain-related disability. Several parent psychological responses (eg, parent catastrophizing about child pain) and behaviours (eg, positive reinforcement of pain, pain modelling) were also identified as critical. A comprehensive understanding of the role of fear-avoidance in pediatric chronic pain necessitates understanding of both child/adolescent and parent factors implicated in its development and maintenance.

\section{CHILD/ADOLESCENT-SPECIFIC FEAR-AVOIDANCE FACTORS}

There have been no comprehensive investigations of the influence of fear-avoidance factors on pediatric chronic pain and disability; however, research has examined the effects of various components of the model, with particular emphasis on psychological responses to pain (eg, pain catastrophizing, anxiety sensitivity, acceptance). In general, pain catastrophizing among children and adolescents has been found to be a relatively consistent predictor of pain-related disability, over and above characteristics of pain; indeed, pain catastrophizing has been shown to explain pain-related disability in children with lower back pain (35), recurrent abdominal pain (36), mixed chronic pain conditions $(37,38)$ and in those from the general population $(38,39)$. Although most of this research has been cross-sectional, similar findings have recently been reported in a prospective study of school-age children (40). In addition to its direct effect on pain-related disability in children with chronic pain, pain catastrophizing has been found to be strongly associated with other important components of the fearavoidance model, such as pain-related anxiety (41) and fear of pain (42).

Child anxiety sensitivity has also been investigated as a psychological characteristic that may amplify fearful reactions to pain, resulting in maladaptive fear and anxiety and, eventually, disability. Anxiety sensitivity is a unique predictor of pain catastrophizing $(43,44)$, pain-related anxiety $(45,46)$ and fear of pain $(42)$ in children and adolescents. It is also related to psychological well-being and social functioning, but not physical disability, in children and adolescents receiving treatment for chronic pain (47). Martin et al (45) failed to observe indirect effects of anxiety sensitivity on disability through fear of pain; however, they did find that anxiety sensitivity significantly predicted fear of pain, which in turn significantly predicted pain-related disability.

With the growing popularity of third-wave psychological interventions, such as acceptance and commitment therapy (ACT) for the treatment of pediatric chronic pain (48), acceptance (ie, how willing an individual is to experience some level of pain in pursuit of greater life goals or values [49]) has also been recognized as an important psychological response that influences the relationship between chronic pain and disability. The fear-avoidance model predicts that continued engagement in activities that are valued by young people such as spending time with friends or participating in physical activity despite some level of pain - should reduce disability and depression. Recent findings support this prediction, showing that acceptance of pain is a significant predictor of pain-related disability and distress in adolescents with chronic pain $(50,51)$. Acceptance, in combination with pain catastrophizing, has also been shown to be predictive of physical and social functioning among adolescents with chronic pain (52). 
The fear-avoidance model also predicts that psychological responses to pain affect pain-related disability through changes in pain-related anxiety and fear of pain (23). Pediatric measures of pain-related anxiety and fear of pain - discussed in more detail below - are relatively new. Nevertheless, research to date has been consistent with predictions of the model, finding that pain-related anxiety and fear of pain are related to, yet distinct from, child/adolescent psychological characteristics (eg, pain catastrophizing and anxiety sensitivity [41,42,53]). Moreover, pain-related anxiety and fear of pain are predictive of painrelated disability in children and adolescents with chronic pain $(42,43,53)$, and pain-related anxiety at the time of surgery has been shown to prospectively predict functional disability for up to several weeks following surgery (46).

Another prediction of the fear-avoidance model is that avoidance of activity will lead not only to functional disability, but also to depression. Consistent with this prediction, a recent meta-analysis revealed that young people with chronic pain experienced higher levels of depressive symptoms than healthy children and adolescents, as well as those who had other chronic health conditions (54). Depression and functional disability are associated in children and adolescents with chronic pain, and pain catastrophizing is a significant predictor of both (6). Furthermore, among young people with chronic pain, characteristics of pain seem to impact depression only to the extent that they result in activity restriction (eg, missing time with friends, not attending school [55]). The relationship between depression and pediatric chronic pain is likely bidirectional; in addition to the impact that chronic pain may have on depression (through activity restriction and functional disability), depression has been identified as a risk factor for the development and maintenance of chronic pain (56).

Research examining child/adolescent-specific factors consistent with the fear-avoidance model of chronic pain has yielded findings largely consistent with those found in adults. However, a significant limitation of the fear-avoidance model when applied to pediatric populations is that it does not directly account for social and familial influences. This is especially relevant in pediatric populations wherein the family is believed to exert a powerful influence on the development and maintenance of chronic pain $(57,58)$. In the following section, we review literature pertinent to the interaction between parent and child/adolescent factors related to the fear-avoidance model, with specific emphasis on the influences of early learning about fear and pain, and parent psychological and behavioural responses to the child's pain experience.

\section{PARENT-CHILD/ADOLESCENT FEAR-AVOIDANCE FACTORS}

Social interactions are critical in determining one's experience and expression of pain $(59,60)$, particularly during early developmental periods marked by dependence on parents. Children's and adolescents' cognitions and beliefs about pain, including fear-avoidance beliefs, are believed to develop within the familial context $(33,57)$. Early learning experiences related to pain convey important information to children and adolescents about its inherent threat value as well as the appropriateness of specific behavioural responses such as avoidance (61). Parent modelling is a powerful mechanism through which fear and avoidance are acquired early in life (ie, by 15 months of age [62]), particularly when there are increased opportunities for vicarious learning of threat associations (eg, among anxious parents who more frequently exhibit anxious behaviours [63]). Early instrumental (ie, reinforcement for sick role behaviours) and vicarious (ie, parent modelling of sick role behaviours) learning experiences regarding somatic symptoms in childhood are related to high levels of anxiety sensitivity in adulthood (64-66). Similarly, instrumental and vicarious learning experiences regarding pain in childhood are predictive of pain-related anxiety in adulthood through their influence on the physical concerns component of anxiety sensitivity (67). Importantly, these early learning processes may be affected by the psychological characteristics of the child.
Pain captures the attention of the individual $(68,69)$ as well as the attention of observers in the social environment $(70,71)$. Observing a child in pain can have a profound influence on parents. As outlined in the empathy framework of Goubert et al (70), observing a child in pain elicits affective responses in parents, which can include self-oriented (eg, distress, anxiety) and other-oriented (eg, sympathy, compassion) responses. These affective responses are influenced by parents' previous personal pain experiences as well as their beliefs and cognitions about pain. When parents perceive a high degree of threat upon witnessing a child in pain, they tend to make higher pain estimations and experience heightened levels of distress (72-74), and this is predictive of pain, distress and disability among children and adolescents $(72,73,75)$. Parent distress may provoke parent escape and avoidance tendencies in an effort to reduce their own distress $(73,76,77)$ and this process may be prioritized to the detriment of efforts to help the child adaptively cope with pain (73).

Among pediatric samples with both acute and chronic pain, certain parent behaviours have generally been shown to increase child and adolescent pain-related behaviour/expression (eg, reassurance, solicitousness, protectiveness, criticism), whereas other parent behaviours have been shown to decrease it (eg, distraction [78-83]). Children and adolescents with chronic pain are more likely than their healthy peers to receive solicitous attention from their parents during illness episodes (84). Similar pain-promoting behaviours, such as protectiveness (ie, attending to pain and/or allowing young people to avoid regular activities), are believed to inadvertently reinforce child pain and are related to higher levels of child functional disability and health care usage $(33,36,85,86)$. These parent behaviours may also increase children's and adolescents' somatic awareness and attention to bodily cues and pain sensations (80).

Parent behaviours may also amplify child cognitions about the threat value of pain (80) and promote increases in pain-related behaviour and avoidance (33). Indeed, parent pain-promoting behaviours (eg, reassurance) have been conceived of as communicative signals of parent fear and anxiety, which can exacerbate child distress $(78,82)$. Parent pain-related behaviours may exert their influence on child functional disability through the psychological characteristics of the child; eg, child anxiety has been shown to moderate the relationship between parent protectiveness and child disability $(81,87)$, suggesting that highly anxious children and adolescents are most susceptible to the adverse impact of these parent behaviours. Furthermore, the relationship between parent protectiveness and activity limitations appears to be mediated by fear-avoidance beliefs of adolescents (33).

A growing body of literature indicates that parent psychological responses strongly influence a child's attention to and interpretation of pain cues, which influences the psychological and behavioural responses of both the parent (eg, self-oriented emotions, distress) and the child in pain (eg, increased pain and disability $[72,73,88,89]$ ). Parent catastrophizing about child pain has been linked to more childhood illness-related parenting stress, anxiety and depression, as well as greater disability and poorer school attendance among children and adolescents, over and above child pain intensity (72). Just as children's catastrophic thoughts about their own pain can instigate escape and avoidance tendencies, this may also be true for parents who catastrophize about their child's chronic pain. Recent research revealed that parents of children and adolescents with chronic pain exhibited a greater behavioural tendency to want to stop their child from engaging in pain-inducing activity, particularly when parents were highly distressed (76); that is, parents who have catastrophic cognitions about their child's pain may preferentially engage in childfocused avoidant tendencies (eg, restriction of child/adolescent activity) in an effort to reduce or escape their own distress. Similarly, the relationship between parent psychological characteristics (eg, helplessness, distress) and child/adolescent functional disability appears to be mediated by parent protective behaviours (90). Research also indicates that parent psychological responses (eg, parenting stress and catastrophizing) indirectly influence child/adolescent functional 


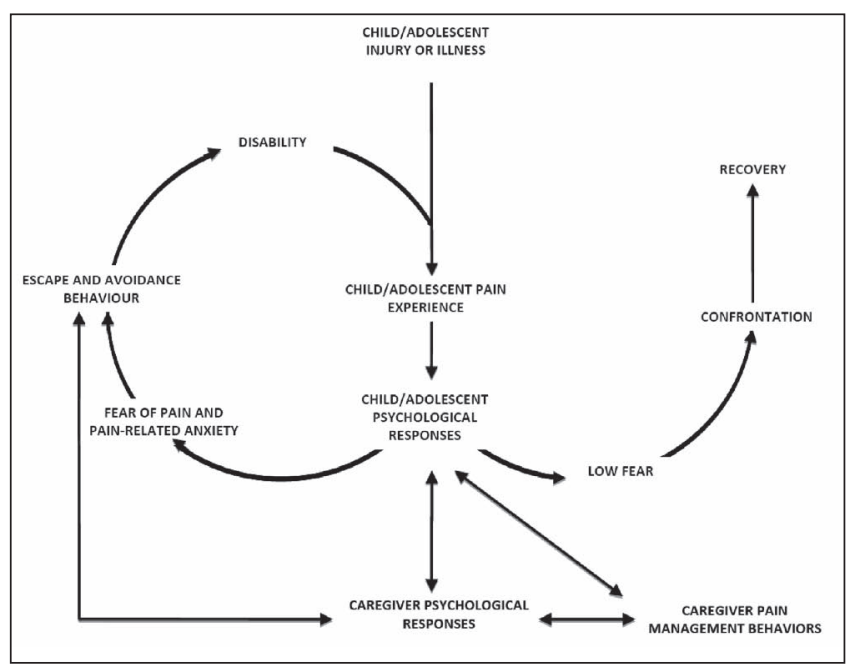

Figure 1) Pediatric fear-avoidance model of chronic pain. Adapted from models presented in Vlaeyen and Linton (21), Asmundson et al (16) and Leeuw et al (23)

disability through child/adolescent - and not parent - responses to pain (52). Conversely, parent psychological responses and behaviours may also serve a protective function. Consistent with the principles underlying ACT, parent psychological flexibility (including acceptance, cognitive defusion, committed and values-based action, and mindfulness) is related to fewer pain-promoting parent behaviours, greater acceptance of pain among adolescents with chronic pain, and better adolescent functioning across social, emotional, familial and developmental domains (91).

It is important to appreciate the complexity inherent in the relationships between the characteristics of children with chronic pain and those of their parents in influencing the child's pain experience. The cross-sectional nature of the majority of research in this area has precluded conclusions regarding the causal pathways and temporal relationships between child/adolescent and parent factors. It is likely that many of these relationships are bidirectional (57), and parent and child/adolescent factors may serve to exacerbate one another in a cyclical manner over time (92). Whereas parent psychological and behavioural responses can influence the child's pain experience, children's and adolescents' fear-avoidance in the context of chronic pain can also adversely affect parents. It is well recognized that parenting a child or adolescent with chronic pain can have a devastating impact on families across social, relational, emotional and financial domains $(93,94)$. Furthermore, these inter-relationships are likely dynamic and should be interpreted within a developmental context $(57,58)$.

\section{PEDIATRIC FEAR-AVOIDANCE MODEL OF CHRONIC PAIN}

Based on the emerging literature pertaining to fear-avoidance in children and adolescents, and recognizing the importance of parent and child factors, amendments to the fear-avoidance model for application to pediatric populations appear to be warranted. The pediatric fear-avoidance model, based on the model of Vlaeyen and Linton (21), is illustrated in Figure 1. The model incorporates several modifications supported by the pediatric literature, recognizing distinct fear/escape and anxiety/avoidance pathways and expanded possible influences of predispositional and current psychological factors. It also maintains the basic premise that responses to pain following injury (or illness) will either involve gradual confrontation to pain and associated recovery or fear-based responding and maintenance of a vicious self-perpetuating cycle characterized by emotional distress, pain and functional disability. The pediatric fear-avoidance model is unique in its emphasis on the reciprocal influences of child and parent factors in the development and maintenance of chronic pain. Specifically, it illustrates the bidirectional relationships between parent pain management behaviours (eg, protectiveness, solicitousness), parent psychological responses (eg, parent catastrophizing about child pain, anxiety sensitivity, general distress) and child/ adolescent psychological responses (eg, catastrophizing, acceptance, anxiety sensitivity) in influencing child/adolescent escape and avoidance behaviours. It is assumed that both child/adolescent and parent psychological responses encompass the individual's overt expression of pain and/or fear, which are important bottom-up influences that can signify threat to the observer and thereby influence the observer's psychological responses and behaviours (70). The model further posits that child/adolescent escape and avoidance behaviours can directly impact parent psychological responses and, indirectly, through parent psychological responses, impact parent pain management behaviours. Furthermore, the model emphasizes the direct impact that parent pain management behaviours (eg, removing children and adolescents from pain-inducing activities) can have on child/adolescent escape and avoidance behaviours, which would likely be most prevalent during earlier developmental periods marked by increased dependence. In essence, the model explains child and adolescent influences on response to pain, parent responses to the child/adolescent experiencing pain, and parent and child/adolescent interactions influencing responses of each to the child's/adolescent's pain. In doing so, the pediatric fear-avoidance model of chronic pain provides a heuristic for continuing empirical evaluation and clinical intervention.

\section{CLINICAL APPLICATIONS}

There is a considerable and compelling foundation of knowledge indicating that interventions targeting clinically significant fear of pain and pain-related anxiety are effective and efficacious in reducing emotional distress and improving function in adults with chronic pain (24). While less developed, there is emerging evidence that ageappropriate interventions for children and adolescents, and their parents, are similarly promising. Available self-report assessment tools as well as potential intervention targets for child/adolescent-specific and parent-child fear-avoidance factors are highlighted below.

\section{Self-report assessment tools}

Many measurement tools relevant to the fear-avoidance model have been designed for use in adult populations (95); however, similar measurement tools for children and adolescents have, until recently, been largely unavailable. While some general measures of pain coping (Pain Coping Questionnaire [96]), pain catastrophizing (Pain Catastrophizing Scale - Child Version [37]; also see more recently available Pain Catastrophizing Scale - Parent Version [72]), and anxiety sensitivity (Childhood Anxiety Sensitivity Index [97]) have been available for a decade or more, only recently have fear of pain and pain-related anxiety measures for children, adolescents and their parents become a specific focus of development and evaluation efforts.

Child/adolescent measures: The Fear of Pain Questionnaire Child and Parent Proxy Report (FOPQ-C and FOPQ-P [53]) was developed using four validated measures from the adult chronic pain literature (ie, Tampa Scale for Kinesophobia [98]; Psychological Inflexibility Scale [99]; Fear Avoidance Beliefs Questionnaire [100]; Pain Anxiety Symptoms Scale-20 [PASS-20] [101]) to assess pain-related fear as reported by children with chronic pain and their parents. The FOPQ-C comprises two factors (fear of pain, avoidance of activities) whereas the FOPQ-P comprises three factors (avoidance of activities, school avoidance and fear of pain). Both the child and parent versions of this measure demonstrate strong internal consistency and stability. Both measures also demonstrate good construct validity; however, it is noteworthy that construct validity of the FOPQ fear of pain subscale was inferred, in part, by assessing its association with a measure of anxiety symptoms (the Multidimensional Anxiety Scale for Children [102]).

The Pediatric Pain Fear Scale (PPFS) (42) is another measure designed to assess the dimensions of pediatric pain-related fear. The 
PPFC was developed from a thorough literature review, consultation with experts, and semistructured interviews with children and adolescents. Initial psychometric evaluation using data from community and clinical samples revealed that the PPFS comprises two factors (fearful thoughts, and fearful physical feelings and behaviours) and demonstrates strong internal consistency and construct validity. Given that behavioural and physiological components of fear are subsumed under a single factor, additional factor analytic evaluation of the measure is warranted.

The PASS-20 (101), a short version of the original Pain Anxiety Symptoms Scale (103), was recently adapted for use with children and adolescents. The adapted measure - the Child Pain Anxiety Symptoms Scale (CPASS [41]) - has a factor structure similar to the original adult measures, comprising four lower-order factors (cognitive, physiological anxiety, fear, escape/avoidance) that load onto a higher-order factor of pain-related anxiety. The CPASS demonstrates strong internal consistency, construct and discriminant validity in nonclinical and clinical samples, and sensitivity to change following surgery $(41,46)$. Further investigation of the factor structure of the CPASS is warranted, particularly in large samples of children and adolescents with various chronic pain conditions.

Parent measures: The Pain-Related Parent Behaviour Inventory (PPBI-C-P [104]) was developed to assess how parent behavioural responses to child/adolescent pain (as perceived by the child/adolescent and the parent) can influence child pain experiences. Exploratory factor analysis revealed three subscales, including solicitous, discouraging and distracting responses. In contrast to previous research, only discouraging responses were associated with higher levels of child anxiety, somatic complaints and catastrophizing in the sample of children and adolescents with recurrent pain. Children and adolescents who used more positive self-statements and problem solving also reported greater parent solicitousness and distracting behaviours, suggesting that these may be interactional styles that promote approach-oriented coping. Other measures of parent behavioural responses to child pain have recently become available (eg, Inventory of Parent/Caregiver Responses to Children's Pain Experience [105]); however, space limitations preclude detailed description of such measures.

The adolescent adaptation of the original Chronic Pain Acceptance Questionnaire (CPAQ) (106) - the CPAQ-A (50) - was developed to assess the level of pain acceptance exhibited by adolescents, demonstrated through participation in daily activities despite the presence of pain (ie, activity engagement) and the absence of attempts to avoid pain (ie, pain willingness). Initial psychometric evaluation of both the adolescent and parent versions (CPAQ-P) (107) demonstrated strong internal consistency and construct validity, and results from the CPAQ-A have since been replicated (51).

Summary: The growing number of measures now available to assess fear-avoidance constructs from the perspective of children/adolescents and their parents is encouraging; however, this line of inquiry and development still lags far behind related adult literature (108). Many of the aforementioned measures lack psychometric evaluation beyond their initial assessment, making the reliability, validity and factor structure of the measurements uncertain. Also potentially problematic is that fear of pain and pain-related anxiety measures tend to share similar item (eg, 'I worry when I am in pain', 'I begin trembling when engaged in an activity that causes pain') and factor (eg, 'avoidance of activities', 'escape/avoidance', 'pain willingness') content, blurring the important distinction between fear, anxiety and other psychological constructs. Finally, adult measures that have been adapted for use with children and adolescents (eg, PCS, CPASS, FOPQ) warrant continuing systematic evaluation to ensure that aspects of measured constructs that may be unique to children and adolescents are not overlooked. These areas require careful consideration in future development and psychometric evaluation of fear of pain, pain-related anxiety, and associated measures for children and adolescents as well as their parents.

\section{Treatment}

The pediatric fear-avoidance model of chronic pain illustrates the complex and bidirectional influences of child/adolescent and parent psychological and behavioural responses on pain-related functional disability in pediatric chronic pain. The model also posits that child/ adolescent escape and avoidance behaviours are the most proximal predictors of functional disability. This suggests that targeting these behaviours should be a main focus of intervention, if that intervention aims to target pain-related functional disability. Child/adolescent psychological responses to pain would also be critical targets for intervention, particularly responses that have been shown to influence pain-related anxiety, fear of pain and functional disability (eg, pain catastrophizing, anxiety sensitivity, acceptance). In addition to child/ adolescent factors, the proposed model suggests that any treatment that aims to most effectively influence functional disability in pediatric chronic pain should also address parent psychological responses and behaviours, which serve to directly and/or indirectly perpetuate the cycle.

Child/adolescent-specific factors and treatment: Most research concerning nonpharmacological interventions for pediatric chronic pain has examined the effectiveness of traditional cognitive-behavioural therapy (CBT) approaches $(109,110)$. CBT-based interventions aim to improve pain management and decrease pain-related disability in pediatric chronic pain patients by teaching coping skills to children/adolescents and behavioural strategies to parents. Psychoeducation regarding biopsychosocial influences on pain, relaxation exercises, positive self-talk, cognitive restructuring and distraction are taught to children and adolescents as ways to facilitate adaptive coping with pain. Through more adaptive coping, treatment aims to decrease negative psychological responses to pain (eg, pain catastrophizing) and increase well behaviours (eg, going to school even when experiencing some level of pain). Treatment also often includes the use of self-monitoring strategies to help children and adolescents assess changes in pain and to identify potential pain triggers. The use of self-reinforcement strategies is also promoted when children are able to successfully cope with pain and/or persist with daily activities despite pain. Additionally, parents learn operant-based behavioural strategies to reinforce children/adolescents for engaging in adaptive well behaviours (discussed in more detail below) (111). Recent reviews of the effects of CBT for chronic pain in children and adolescents indicate that these interventions are effective in reducing pain intensity; however, there is little supportive evidence that they result in significant decreases in functional disability or increases in emotional functioning $(109,110)$. Although it has been argued that this latter finding may be a result of methodological issues, such as failure to regularly measure these outcomes (110), it is also possible that traditional CBT does not adequately emphasize changes in escape and avoidance behaviours theorized to directly impact functional disability. Research has, therefore, moved toward examining new treatment approaches that aim to reduce the functional and emotional impact of pediatric chronic pain on families.

The ACT approach, which is largely consistent with the fearavoidance model presented herein, suggests that escape and avoidance behaviours occur when negative thoughts and emotions (eg, pain catastrophizing, fear of pain and pain-related anxiety) have an excessive or inappropriate impact on behaviour (48). This leads children and adolescents with chronic pain to avoid meaningful and valued activities because they are potentially painful and fear provoking (112). Treatment, therefore, emphasizes exposure to previously avoided activities that are consistent with the individual's values. Rather than trying to change negative psychological responses to pain, treatment encourages acceptance of certain aspects of chronic pain that cannot be directly changed (eg, some pain, fatigue, negative thoughts and emotions) as a way to modify aspects that can be changed (eg, engaging in activities that are consistent with the individual's values). As such, this approach directly targets escape and avoidance behaviours as well as psychological responses to pain (eg, acceptance). A 
recent randomized controlled trial indicated that ACT was as efficacious as longer duration multidisciplinary interventions (ie, traditional CBT techniques plus medication) in reducing functional disability, and had greater efficacy in reducing pain-related impairment, discomfort and pain intensity (48).

This approach to pediatric chronic pain management emphasizes graded exposure to important activities that children have avoided for fear that they may cause pain and distress. Findings are consistent with the adult literature, which suggests that graded exposure to feared situations and ACT are currently the most empirically supported treatments for fear of pain and pain-related anxiety (24). Interoceptive exposure to painful and other anxiety-provoking bodily sensations has also been suggested to reduce anxiety sensitivity as well as pain-related anxiety (113). Preliminary research with pediatric populations suggests that when interoceptive exposure (in addition to bilateral tactile stimulation and imagery involving adolescents' use of coping strategies) was used as an adjunct to standard multimodal treatment, it resulted in lower pain intensity and similar reductions in pain-related disability among adolescents with chronic pain (114).

Parent-child/adolescent factors and treatment: Given the integral role of family in children and adolescents' pain experience, parent behavioural training is often incorporated into evidence-based psychological treatments for pediatric chronic pain. Parent behavioural training, in the context of CBT, involves teaching operantbased behavioural strategies to parents that aim to decrease pain behaviours and foster well behaviours and developmentally appropriate coping among children and adolescents (111); eg, parents are taught to attend to and reward children and adolescents for engaging in well behaviours and to model well behaviours themselves. As such, these interventions may facilitate the adoption of parent behaviours that encourage children and adolescents to expose themselves to activities that they previously avoided, albeit without the use of graded exposure.

The involvement of parents in existing CBT-based interventions for pediatric chronic pain is based on the assumption that parents are able to modify their existing behavioural responses; however, this may be particularly difficult for highly distressed parents (115). Parents of children and adolescents with chronic pain often live in stressful environments (116) and are likely to have their own mental health needs (eg, depression, anxiety, somatization [93]). Given that chronic and recurrent pain often runs in families (117-119), parents themselves may have fear-avoidance beliefs and behaviours that interact with those of their child. The pediatric fear-avoidance model of chronic pain predicts that the vicious and self-perpetuating cycle would be especially entrenched among families wherein both the parents and child/adolescent have catastrophic and fearful cognitions about pain (see reciprocal relationships among child/adolescent psychological responses/expression, parent psychological responses/ expression and parent pain management behaviours in Figure 1). Parents with high levels of anxiety sensitivity are likely to have been reinforced for their own somatization in early childhood (64-66) and are at risk for developing fear of pain and catastrophic thoughts about pain (16). Furthermore, parents who catastrophize about their child's chronic pain are more likely to experience self-oriented responses (eg, distress), which may instigate their own escape and avoidance behaviours $(73,76,77)$. Particularly early in development, these escape and avoidance behaviours could include removing children from pain-inducing activities, which would directly promote escape and avoidance behaviours in children (see direct path from parent pain management behaviours to escape and avoidance behaviour in Figure 1). This highlights the potential value of exposure-based interventions aimed at reducing parents' distress, catastrophic cognitions about pain and escape and avoidance behaviours.

There is growing recognition of the importance of addressing and managing parent distress in interventions for pediatric chronic pain to more effectively manage child/adolescent pain and disability
$(90,116)$. Nevertheless, unlike treatments for other chronic medical conditions, the majority of interventions for pediatric chronic pain have focused on parenting practices without adequate consideration of parents' emotional needs (116). Recent research highlights the potential value of inclusion of parent training within ACT approaches, given the importance of parent psychological flexibility in adolescents' chronic pain experience (91). Interventions could involve promoting parents' acceptance of distress associated with their child's chronic pain, limiting parents' reactions to their own and their child's distress, maintaining parents' focus on the present moment without becoming consumed with worry and prioritizing actions driven by broader goals and values (eg, attending school, socializing with peers) versus catastrophic thoughts and distress (eg, restricting social activities [91]).

Summary: The pediatric fear-avoidance model of chronic pain emphasizes the importance of exposure to avoided activities in treating children and adolescents with chronic pain. This model also calls for the use of interventions that reduce negative psychological responses, such as traditional CBT techniques (eg, cognitive restructuring) for decreasing pain catastrophizing, ACT techniques for increasing acceptance, and interoceptive exposure for reducing fear of bodily sensations (ie, anxiety sensitivity). Given the complex and reciprocal influences of child/adolescent and parent factors in the exacerbation of pediatric chronic pain and disability (57), interventions designed to address fear-avoidance in both the parent and child/adolescent appear particularly promising. These novel treatment approaches warrant further empirical investigation but, nonetheless, hold promise for reducing the functional and emotional impact of pediatric chronic pain by targeting the complex and underlying processes involved in its development and maintenance.

\section{CONCLUSION AND FUTURE DIRECTIONS}

The development of the pediatric fear-avoidance model was largely informed by recent compelling evidence supporting the reciprocal relationships between child/adolescent and parent psychological and behavioural responses in influencing pediatric chronic pain. Given the relative novelty of most of this research, there are several important areas for future empirical investigation. First, the pediatric fear-avoidance model, similar to the model of Vlaeyen and Linton (21) on which it is based, is rooted in cognitive and behavioural work, and focuses on the psychological and behavioural factors implicated in the development and maintenance of chronic pain. It is, nevertheless, important to acknowledge and investigate the dynamic interactions that exist between biological factors, psychological factors and behavioural responses of both parents and children in exacerbating this vicious cycle (120). Second, the majority of the evidence that informed the development of the model was based on cross-sectional investigations of fear-avoidance constructs in isolation of one another. The use of prospective longitudinal designs and comprehensive examinations of child/adolescent and parent fear-avoidance factors are needed to support the directionality of the pathways as currently depicted. Third, although the model does not explicitly acknowledge the roles of child/adolescent and parent sex in moderating the relationships between child/adolescent and parent factors, this is an important area for further inquiry. Indeed, there is emerging evidence documenting the influence of child/adolescent sex on several fear-avoidance constructs (catastrophizing, pain-related anxiety, anxiety sensitivity $[3,44]$ ) as well as the differential influences of maternal versus paternal behaviours in child/adolescent chronic pain experiences (121). Fourth, given that many of the self-report tools used to assess fear-avoidance constructs in pediatric populations have only very recently been developed, and there is considerable overlap in content across measures, research is needed to further refine these instruments and examine their clinical utility. Fifth, it is critical that a developmental perspective is applied to the understanding and examination of the model. The inter-relationships between parent and child/adolescent factors are likely dynamic and may change as adolescents progress toward emerging adulthood and as pain transitions from acute to chronic. 
Given the importance of peer relationships during adolescence, which is marked by increased autonomy from parents, future research should examine peer influences in fear-avoidance during this developmental period. This is particularly important in light of evidence suggesting that peer relationships are impaired among adolescents with chronic pain (11). Finally, there are several promising treatment approaches for both children/adolescents and parents (eg, exposure, ACT-based approaches, distress reduction) which could be combined with components of existing CBT protocols to maximize the effectiveness of interventions on emotional and functional outcomes. It is our hope that the pediatric fear-avoidance model of chronic pain will inspire the advancement of research and generation of empirical knowledge to ultimately lessen the suffering of children and adolescents as well as their families.

ACKNOWLEDGEMENTS: MN and MP are supported by Frederick Banting and Charles Best Canada Graduate Scholarships Doctoral Awards from the Canadian Institutes of Health Research (CIHR), honorary Killam Predoctoral Scholarships, and are also trainee members of Pain in Child Health (PICH), a Strategic Training Initiative in Health Research of the CIHR. HAP is supported by a Frederick Banting and Charles Best Canada Graduate Scholarships Master's Award.

\section{REFERENCES}

1. Katz J, McCartney CJL Rashiq S. Why does pain become chronic? In: Taenzer P, Rashiq S, Schopflocher D, Jonsson E, eds. Health Policy Perspectives on Chronic Pain. Weinheim: Wiley-Blackwell, 2008:69-84.

2. International Association for the Study of Pain (IASP). Classification of chronic pain. Descriptions of chronic pain syndromes and definitions of terms. Pain 1986;Suppl 3:51-226.

3. Fuss S, Pagé MG, Katz J. Persistent pain in a community-based sample of children and adolescents: Sex differences in psychological constructs. Pain Res Manag 2011;16:303-9.

4. Breivik H, Collett B, Ventafridda V, Cohen R, Gallacher D. Survey of chronic pain in Europe: Prevalence, impact on daily life, and treatment. Eur J Pain 2006;10:287-333.

5. Gureje O, Von Korff M, Simon GE, Gater R. Persistent pain and well-being: A world health organization study in primary care. JAMA 1998;280:147-51.

6. Kashikar-Zuck S, Goldschneider KR, Powers SW, Vaught MH, Hershey AD. Depression and functional disability in chronic pediatric pain. Clin J Pain 2001;17:341-9.

7. Perquin CW, Hunfeld JAM, Hazebroek-Kampschreur AAJM, et al. Insights in the use of health care services in chronic benign pain in childhood and adolescence. Pain 2001;94:205-13.

8. Fichtel A, Larsson B. Psychosocial impact of headache and comorbidity with other pains among Swedish school adolescents. Headache 2002;42:766-75.

9. Asmundson GJG, Katz J. Understanding the co-occurrence of anxiety disorders and chronic musculoskeletal pain: The state-ofthe-art. Depress Anxiety 2009;26:888-901.

10. Dick BD, Pillai Riddell R. Cognitive and school functioning in children and adolescents with chronic pain: A critical review. Pain Res Manag 2010;15:238-44.

11. Forgeron PA, King S, Stinson JN, McGrath PJ, MacDonald AJ, Chambers CT. Social functioning and peer relationships in children and adolescents with chronic pain: A systematic review. Pain Res Manag 2010;15:27-41.

12. Turk DC, Rudy TE. Towards a comprehensive assessment of chronic pain patients. Behav Res Ther 1987;25:237-49.

13. Asmundson GJG, Norton GR, Allerdings MD, Norton PJ, Larsen DK. Posttraumatic stress disorder and work-related injury. J Anxiety Disord 1998;12:57-69.

14. Huguet A, Miró J. The severity of chronic pediatric pain: An epidemiology study. J Pain 2008;9:226-36.

15. Barlow DH. Anxiety and Its Disorders, 2nd edn. New York: Guilford Press, 2002.

16. Asmundson GJG, Norton PJ, Vlaeyen JWS. Fear-avoidance models of chronic pain: An overview. In: Asmundson GJG, Vlaeyen JWS, Crombez G, eds. Understanding and Treating Fear of Pain. New York: Oxford University Press, 2004:3-24.

17. McCracken LM, Gross RT, Aikens J, Carnrike CLM. The assessment of anxiety and fear in persons with chronic pain: A comparison of instruments. Behav Res Ther 1996;34:927-33.
18. Carleton RN, Asmundson GJG. The multidimensionality of fear of pain: Construct independent for the fear of pain questionnaireshort form and the pain anxiety symptoms scale-20. J Pain 2009;10:29-37.

19. Morley S, Eccleston C. The object of fear of pain. In: Asmundson GJG, Vlaeyen JWS, Crombez G, eds. Understanding and treating fear of pain. Oxford UK: Oxford University Press; 2004:163-88.

20. Asmundson GJG, Norton PJ, Norton GR. Beyond pain: The role of fear and avoidance in chronicity. Clin Psychol Rev 1999;19:97-119.

21. Vlaeyen JWS, Linton SJ. Fear-avoidance and its consequences in chronic musculoskeletal pain: A state of the art. Pain 2000;85:317-32.

22. Asmundson GJG, Vlaeyen JWS, Crombez G. Understanding and Treating Fear of Pain. New York: Oxford University Press, 2004.

23. Leeuw M, Grossman ME, Linton SJ, Crombez G, Boersma K, Vlaeyen JWS. The fear-avoidance model of musculoskeletal pain: Current state of scientific evidence. J Behav Med 2007;30:77-94.

24. Bailey KM, Carleton RN, Vlaeyen JWS, Asmundson GJG. Treatments addressing pain-related fear and anxiety in patients with chronic musculoskeletal pain: A preliminary review. Cogn Behav Ther 2010;39:46-63.

25. Turk DC, Wilson HD. Fear of pain as a prognostic factor in chronic pain: Conceptual models, assessment, and treatment implications. Curr Pain Headache Rep 2010;14:88-95.

26. Norton PJ, Asmundson GJG. Anxiety sensitivity, fear, and avoidance behavior in headache pain. Pain 2004;111:218-23.

27. Goubert L, Crombez G, Van Damme S, Vlaeyen JWS, Bijttebier P, Roelofs J. Confirmatory factor analysis of the tampa scale for kinesiophobia: Invariant two-factor model across low back pain patients and fibromyalgia patients. Clin J Pain 2004;20:103-10.

28. Sgroi MI, Willebrand M, Ekselius L, Gerdin B, Andersson G. Fear-avoidance in recovered burn patients: Association with psychological and somatic symptoms. J Health Psychol 2005;10:491-502.

29. Norton PJ, Asmundson GJG. Amending the fear-avoidance model of chronic pain: What is the role of physiological arousal? Behav Ther 2003;34:17-30.

30. Asmundson GJG, Taylor S. Role of anxiety sensitivity in painrelated fear and avoidance. J Behav Med 1996;19:577-86.

31. Greenberg J, Burns JW. Pain anxiety among chronic pain patients: Specific phobia or manifestation of anxiety sensitivity? Behav Res Ther 2003;41:223-40.

32. Palermo TM, Witherspoon D, Valenzuela D, Drotar DD. Development and validation of the Child Activity Limitations Interview: A measure of pain-related functional impairment in school-age children and adolescents. Pain 2004;109:461-70.

33. Wilson AC, Lewandowski AS, Palermo TM. Fear-avoidance beliefs and parental responses to pain in adolescents with chronic pain. Pain Res Manag 2011;16:178-82.

34. Miró J, Huguet A, Nieto R. Predictive factors of chronic pediatric pain and disability: A Delphi poll. J Pain 2007;8:774-92.

35. Lynch AM, Kashikar-Zuck S, Goldschneider KR, Jones BA. Psychosocial risks for disability in children with chronic back pain. J Pain 2006;7:244-51.

36. Langer SL, Romano JM, Levy RL, Walker LS, Whitehead WE. Catastrophizing and parental response to child symptom complaints. Child Health Care 2009;38:169-84.

37. Crombez G, Bijttebier P, Eccleston C, et al. The child version of the pain catastrophizing scale (PSC-C): A preliminary validation. Pain 2003;104:639-46.

38. Vervoort T, Goubert L, Eccleston C, Bijttebier P, Crombez G. Catastrophic thinking about pain is independently associated with pain severity, disability, and somatic complaints in school children and children with chronic pain. J Pediatric Psychol 2006;31:674-83.

39. Huguet A, Eccleston C, Miró J, Gauntlett-Gilbert J. Young people making sense of pain: Cognitive appraisal, function, and pain in 8-16 year old children. Eur J Pain 2009;13:751-9.

40. Vervoort T, Eccleston C, Goubert L, Buysse A, Crombez G. Children's catastrophic thinking about their pain predicts pain and disability 6 months later. Eur J Pain 2010;14:90-6.

41. Pagé MG, Fuss S, Martin AL, Escobar EMR, Katz J. Development and preliminary validation of the Child Pain Anxiety Symptoms Scale in a community sample. J Pediatric Psychol 2010;35:1071-82.

42. Huguet A, McGrath PJ, Pardos J. Development and preliminary testing of a scale to assess pain-related fear in children and adolescents. J Pain 2011;12:840-8. 
43. Muris P, Meesters C, van den Hout A, Wessels S, Franken I, Rassin E. Personality and temperament correlates of pain catastrophizing in young adolescents. Child Psychiatry Human Dev 2007;38:171-81.

44. Tsao JCI, Allen LB, Evans S, Lu Q, Myers CD, Zeltzer LK. Anxiety sensitivity and catastrophizing associations with pain and somatization in non-clinical children. J Health Psychol 2009;14:1085-94.

45. Martin AL, McGrath PA, Browns SC, Katz J. Anxiety sensitivity, fear of pain and pain-related disability in children and adolescents with chronic pain. Pain Res Manag 2007;12:267-72.

46. Page MG, Campbell F, Isaac L, Stinson J, Martin-Pichora AL, Katz J. Reliability and validity of the Child Pain Anxiety Symptoms Scale (CPASS) in a clinical sample of children and adolescents with acute postsurgical pain. Pain 2011;152:1958-65.

47. Tsao JCI, Meldrum M, Kim SC, Zeltzer LK. Anxiety sensitivity and health-related quality of life in children with chronic pain. J Pain 2007;8:814-23.

48. Wicksell RK, Melin L, Lekander M, Olsson GL. Evaluating the effectiveness of exposure and acceptance strategies to improve functioning and quality of life in longstanding pediatric pain: A randomized controlled trial. Pain 2009;141:248-57.

49. Dahl J, Wilson KG, Luciano C. Acceptance and commitment therapy for chronic pain. Reno: Context Press, 2005.

50. McCracken LM, Gauntlett-Gilbert J, Eccleston C. Acceptance of pain in adolescents with chronic pain: Validation of an adapted assessment instrument and preliminary correlation analyses. Eur J Pain 2010;14:316-20.

51. Wallace DP, Harbeck-Weber C, Whiteside SPH, Harrison TE. Adolescent acceptance of pain: Confirmatory factor analysis and further validation of the Chronic Pain Acceptance Questionnaire, Adolescent Version. J Pain 2011;12:591-9.

52. Vowles KE, Cohen LL, McCracken LM, Eccleston C. Disentangling the complex relations among caregiver and adolescent responses to adolescent chronic pain. Pain 2010;151:680-6.

53. Simons LE, Sieberg CB, Carpino E, Logan D, Berde C. The Fear of Pain Questionnaire (FOPQ): Assessment of pain-related fear among children and adolescents with chronic pain. J Pain 2011;12:677-86.

54. Pinquart M, Shen Y. Depressive symptoms in children and adolescents with chronic physical illness: An updated meta-analysis. J Pedatr Psychol 2010;36:375-84.

55. Walters AS, Williamson GM. The role of activity restriction in the association between pain and depression: A study of pediatric patients with chronic pain. Child Health Care 1999;28:33-50.

56. Stanford EA, Chambers CT, Biesanz JC, Chen E. The frequency, trajectories and predictors of adolescent recurrent pain: A population-based approach. Pain 2008;138:11-21.

57. Palermo TM, Chambers CT. Parent and family factors in pediatric chronic pain and disability: An integrative approach. Pain 2005;119:1-4.

58. McGrath PJ. The family is the crucible. Pain 2008;137:471-2.

59. Craig KD. A social communications model of pain. Can Psychol 2009;50:22-32

60. Hadjistavropoulos T, Craig KD, Duck S, et al. A biopsychosocial formulation of pain communication. Psychol Bull 2011;137:910-39.

61. Goubert L, Vlaeyen JWS, Crombez G, Craig KD. Learning about pain from others: An observational learning account. J Pain 2011;12:167-74.

62. Gerull FC, Rapee MM. Mother knows best: Effects of maternal modeling on the acquisition of fear and avoidance behavior in toddlers. Behav Res Ther 2002;40:279-87.

63. Muris P, Steerneman P, Merckelbach H, Meesters C. The role of parental fearfulness and modeling in children's fear. Behav Res Ther 1996;34:265-8.

64. Watt MC, Stewart SH. Anxiety sensitivity mediates the relationship between childhood learning experiences and the development of hypochondriacal concerns in young adulthood. J Psychosom Res 2000;48:1-12.

65. Stewart SH, Taylor S, Jang KL, et al. Causal modeling of relations among learning history, anxiety sensitivity, and panic attacks. Behav Res Ther 2001;39:443-56.

66. Watt MC, O'Connor R, Stewart S, Moon E, Terry L. Specificity of childhood learning experiences related to anxiety sensitivity and illness/injury sensitivity: Implications for health anxiety and pain. J Cog Psychother 2008;39:128-42.

67. Watt MC, Stewart S, Moon E, Terry LL. Childhood learning history origins of adult pain anxiety. J Cog Psychother 2010;24:198-212.
68. Eccleston C, Crombez G. Pain demands attention: A cognitiveaffective model of the interruptive function of pain. Psychol Bull 1999;125:356-66.

69. Van Damme S, Legrain V, Vogt J, Crombez G. Keeping pain in mind: A motivational account of attention to pain. Neurosci Biobehav Rev 2010;34:204-13.

70. Goubert L, Craig KD, Vervoort T, et al. Facing others in pain: The effects of empathy. Pain 2005;118:285-8.

71. Hadjistavropoulos T, Craig KD. A theoretical framework for understanding self report and observational measures of pain A communication model. Behav Res Ther 2002;40:551-70.

72. Goubert L, Eccleston C, Vervoort T, Jordan A, Crombez G. Parental catastrophizing about their child's pain: The parent version of the pain catastrophizing scale. Pain 2006;123:254-63.

73. Goubert L, Vervoort T, Sullivan MJL, Verhoeven K, Crombez G. Parental emotional responses to their children's pain: The role of dispositional empathy and catastrophizing about their childrens pain. J Pain 2008;3:227-79.

74. Guite JW, Logan DE, McCue R, Sherry DD, Rose JB. Parental beliefs and worries regarding adolescent chronic pain. Clin J Pain 2009;25:223-32.

75. Logan DE, Scharff L. Relationships between family and parent characteristics and functional abilities in children with recurrent pain syndromes: An investigation of the moderating effects on the pathway from pain to disability. J Pediatr Psychol 2005;30:698-707.

76. Caes L, Vervoort T, Eccleston C, Vandenhende M, Goubert L. Parental catastrophizing about child's pain and its relationship with activity restriction: The mediating role of parental distress. Pain 2011;152:212-22.

77. Vervoort T, Caes L, Crombez G, et al. Parental catastrophizing about children's pain and selective attention to varying levels of facial expression of pain in children: A dot-probe study. Pain 2011;15251-7.

78. Chambers CT, Craig KD, Bennett SM. The impact of maternal behavior on children's pain experiences: An experimental analysis. J Pediatr Psychol 2002;27:293-301.

79. Chambers CT. The role of family factors in pediatric pain. In: McGrath P, Finley A, eds. Pediatric Pain: Biological and Social Context. Seattle: IASP Press, 2003.

80. Walker LS, Williams SE, Smith CA, Garber J, Van Slyke DA, Lipani TA. Parent attention versus distraction: Impact on symptom complaints by children with and without chronic functional abdominal pain. Pain 2006;122:43-52.

81. Claar RL, Simons LE, Logon DE. Parental response to children's pain: The moderating impact of children's emotional distress on symptoms and disability. Pain 2008;138:172-9.

82. McMurtry CM, Chambers CT, McGrath PJ, Asp E. When “don't worry" communicates fear: Children's perceptions of parental reassurance and distraction during a painful medical procedure. Pain 2010;150:52-8.

83. Simons LE, Claar RL, Logan DL. Chronic pain in adolescence: Parental responses, adolescent coping, and their impact on adolescents pain behaviors. J Pediatr Psychol 2008;33:894-904.

84. Walker LS, Garber J, Greene JW. Psychosocial characteristics of recurrent childhood pain: A comparison of children with recurrent abdominal pain, organic illness, and psychiatric disorders. J Abnorm Psychol 1993;102:248-58.

85. Walker LS, Claar RL, Garber J. Social consequences of children's pain: When do they encourage symptom maintenance? J Pediatr Psychol 2002;27:689-98.

86. Walker LS, Levy RL, Whitehead WE. Validation of a measure of protective parent responses to children's pain. Clin J Pain 2006;22:712-6.

87. Peterson CC, Palermo TM. Parental reinforcement of recurrent pain: The moderating impact of child depression and anxiety on functional disability. J Pediatr Psychol 2004;29:331-41.

88. Goubert L, Vervoort T, Cano A, Crombez G. Catastrophizing about their children's pain is related to higher parent-child congruency in pain ratings: An experimental investigation. Eur J Pain 2009;13:196-209.

89. Goubert L, Vervoort T, Crombez G. Pain demands attention from others: The approach/avoidance paradox. Pain 2009;143:5-9.

90. Sieberg CB, Williams S, Simons LE. Do parent protective responses mediate the relation between parent distress and child functional disability among children with chronic pain? J Pediatr Psychol 2011;36:1043-51. 
91. McCracken LM, Gauntlett-Gilbert J. Role of psychological flexibility in parents of adolescents with chronic pain: Development of a measure and preliminary correlation analyses. Pain 2011;152:780-5.

92. Guite JW, McCue RL, Sherker JL, Sherry DD, Rose JB. Relationships among pain, protective parental responses, and disability for adolescents with chronic musculoskeletal pain: The mediating role of pain catastrophizing. Clin J Pain 2011;27:775-81.

93. Campo JV, Bridge J, Lucas A, et al. Physical and emotional health of mothers of youth with functional abdominal pain. Arch Pediatr Adolesc Med 2007;161:131-7.

94. Palermo TM. Impact of recurrent and chronic pain on child and family daily functioning: A critical review of the literature. J Devel Behav Pediatr 2000;21:58-69.

95. McNeil DW, Vowles KE. Assessment of fear and anxiety associated with pain: Conceptualization, methods, and measures. In: Asmundson GJG, Vlaeyen JWS, Crombez G, eds. Understanding and treating fear of pain. New York: Oxford University Press, 2004:189-211.

96. Reid GJ, Gilbert CA, McGrath PJ. The Pain Coping Questionnaire: preliminary validation. Pain 1998;76:83-96.

97. Silverman WK, Fleisig W, Rabian B, Peterson RA. Childhood anxiety sensitivity index. J Clin Child Psychol 1991;20:162-8

98. Roelofs J, Sluiter JK, Frings-Dresen MHW, et al. Fear of movement and (re)injury in chronic musculoskeletal pain: Evidence for an invariant two-factor model of the Tampa Scale for Kinesiophobia across pain diagnoses and Dutch, Swedish, and Canadian samples. Pain 2007;131:181-90.

99. Wicksell RK, Renofalt J, Olsson GL, Bond FW, Melin L. Avoidance and cognitive fusion: Central components in pain related disability? Development and preliminary validation of the Psychological Inflexibility in Pain Scale (PIPS). Eur J Pain 2008;12:491-500.

100. Waddell G, Newton M, Henderson I, Somerville D, Main CJ. A fear-avoidance beliefs questionnaire (FABQ) and the role of fearavoidance beliefs in chronic low-back-pain and disability. Pain 1993;52:157-68.

101. McCracken LM, Dhingra L. A short version of the pain anxiety symptoms scale (PASS-20): Preliminary development and validity. Pain Res Manag 2002;7:45-50.

102. March JS, Parker JDA, Sullivan K, Stallings P, Conners CK. The multidimensional anxiety scale for children (MASC): Factor structure, reliability, and validity. J Am Acad Child Adolesc Psychiatry 1997;36:554-65.

103. McCracken LM, Zayfert C, Gross RT. The pain anxiety symptoms scale: Development and validation of a scale to measure fear of pain. Pain 1992;50:67-73.

104. Hermann C, Zohsel K, Hohmeister J, Flor H. Dimensions of painrelated parent behavior: Development and psychometric evaluation of a new measure for children and their parents. Pain 2008;137:689-99.

105. Huguet A, Miró J, Nieto R. The inventory of parent/caregiver responses to the children's pain experience (IRPEDNA): Development and preliminary validation. Pain 2008;134:128-39.
106. McCracken LM, Vowles KE, Eccleston C. Acceptance of chronic pain: Component analysis and a revised assessment method. Pain 2004;107:159-66.

107. Simons LE, Sieberg CB, Kaczynski KJ. Measuring parent beliefs about child acceptance of pain: A preliminary validation of the chronic pain acceptance questionnaire, parent report. Pain 2011;152:2294-300.

108. McCracken LM. Pain-related anxiety in children and adolescents: Mind the gap. Pain 2011;152:1938-9.

109. Eccleston C, Palermo T, Williams AC, Lewandowski A, Morley S. Psychological therapies for the management of chronic and recurrent pain in children and adolescents. Cochrane Database Syst Rev 2009(2):CD003968-CD003968.

110. Palermo TM, Eccleston C, Lewandowski AS, Williams ACdC, Morley S. Randomized controlled trials of psychological therapies for management of chronic pain in children and adolescents: An updated meta-analytic review. Pain 2010;148:387-97.

111. Noel M, Petter M, Parker JA, Chambers CT. Cognitive behavioural therapy for pediatric chronic pain: The problem, research, and practice. J Cog Psychother 2012;26:143-56.

112. Wicksell RK, Melin L, Olsson GL. Exposure and acceptance in the rehabilitation of adolescents with idiopathic chronic pain: A pilot study. Pain 2007;11:267-74.

113. Asmundson GJG. Anxiety sensitivity and chronic pain: Empirical findings, clinical implications, and future directions. In: Taylor S, ed. Anxiety Sensitivity: Theory, Research and Treatment of Fear and Anxiety. New Jersey: Erlbaum, 1999:269-85.

114. Hechler T, Dobe M, Damschen U, et al. The pain provocation technique for adolescents with chronic pain: Preliminary evidence for its effectiveness. Pain Med 2010;11:897-910.

115. Jordan AL, Eccleston C, Osborn M. Being a parent of the adolescent with complex chronic pain: An interpretative phenomenological analysis. Eur J Pain 2007;11:49-56.

116. Palermo TM, Eccleston C. Parents of children and adolescents with chronic pain. Pain 2009;146:15-17.

117. Turkat ID, Kuckzmiercczyk AR, Adams HE. An investigation of the aetiology of chronic headache. The role of headache models. Br J Psychiatry 1984;145:665-6.

118. Goodman JE, McGrath PJ, Forward SP. Aggregation of pain complaints and pain-related disability and handicap in a community sample of families. In: Jensen TS, Turnjer JA, Wiesenfeld-Hallin Z, eds. Progress in Pain Research and Management. Seattle: IASP Press, 1997:673-82.

119. Levy RL. Exploring the intergenerational transmission of illness behavior: From observations to experimental intervention. Ann Behav Med 2011;41:174-82.

120. Fitzgerald M. The neurobiology of chronic pain in children. In: McClain BC, Suresh S, eds. Handbook of Pediatric Chronic Pain: Current Science and Integrative Practice. New York: Springer, 2011:15-25.

121. Hechler T, Vervoort T, Hamann M, et al. Parental catastrophizing about their child's chronic pain: Are mothers and fathers different? Eur J Pain 2011;515e1-9. 


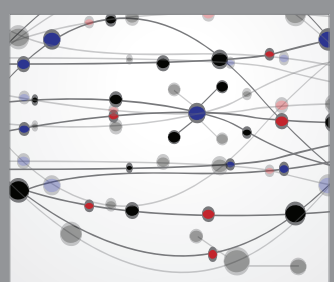

The Scientific World Journal
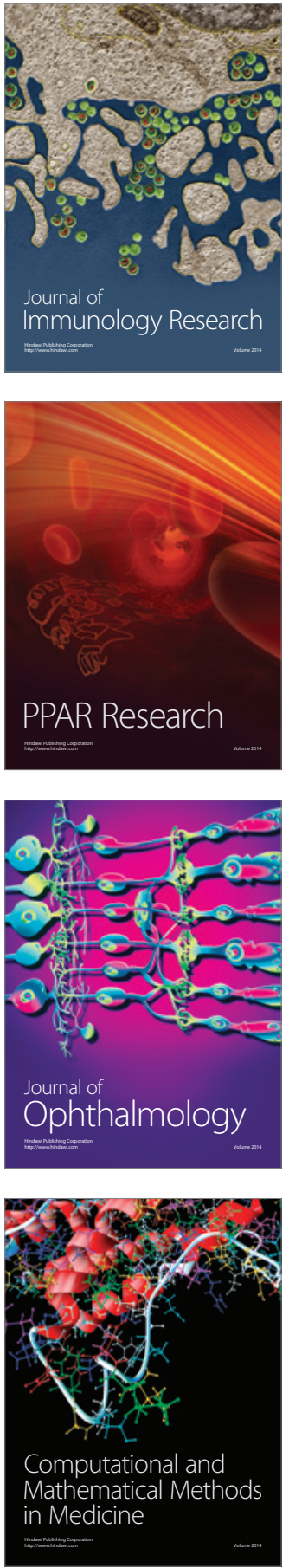

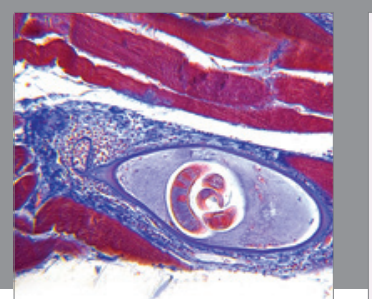

Gastroenterology Research and Practice

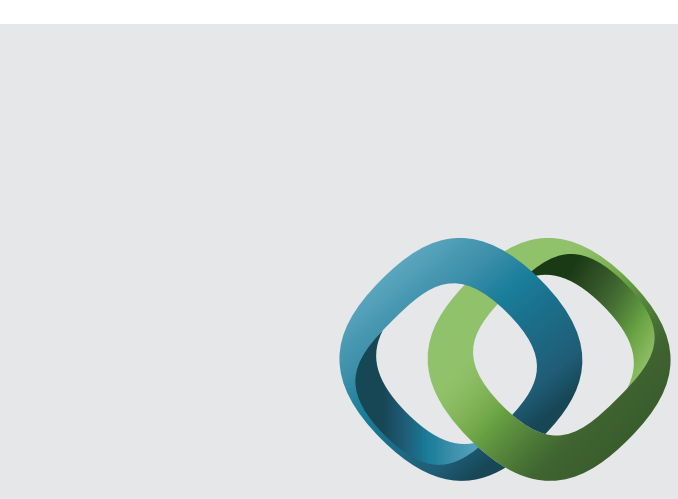

\section{Hindawi}

Submit your manuscripts at

http://www.hindawi.com
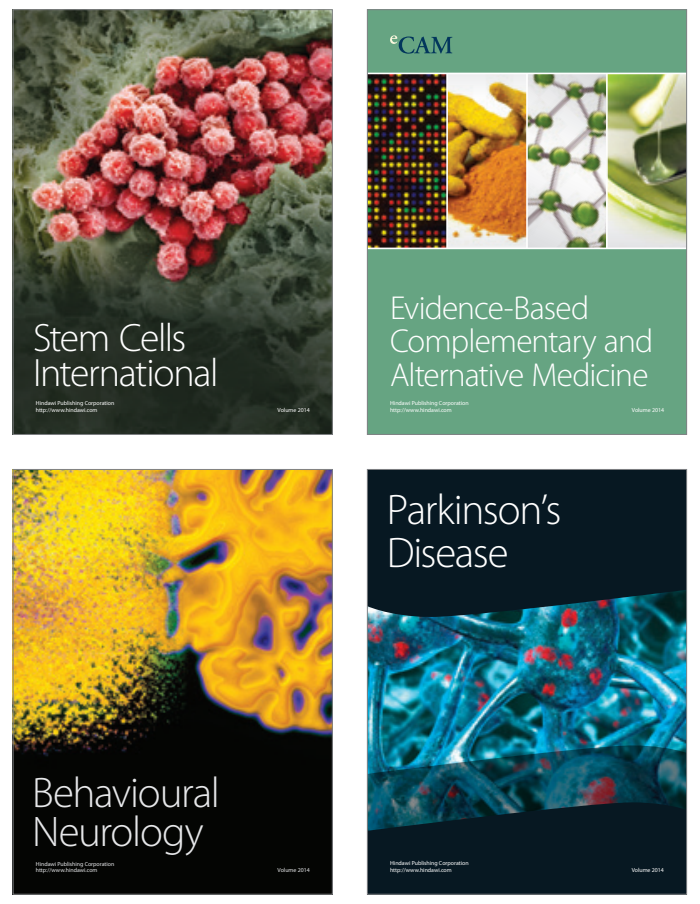
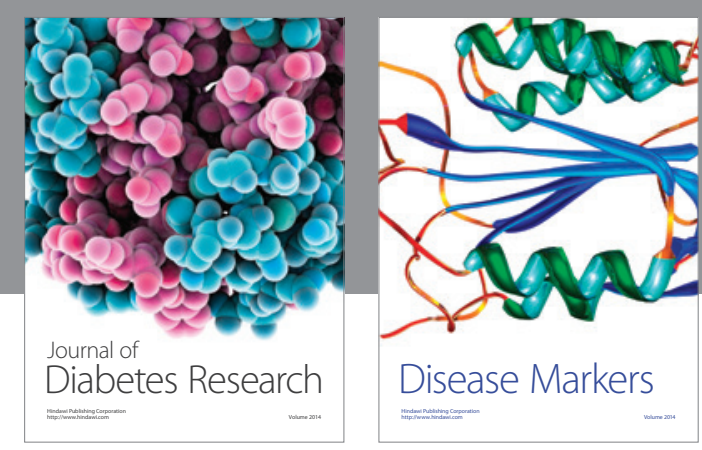

Disease Markers
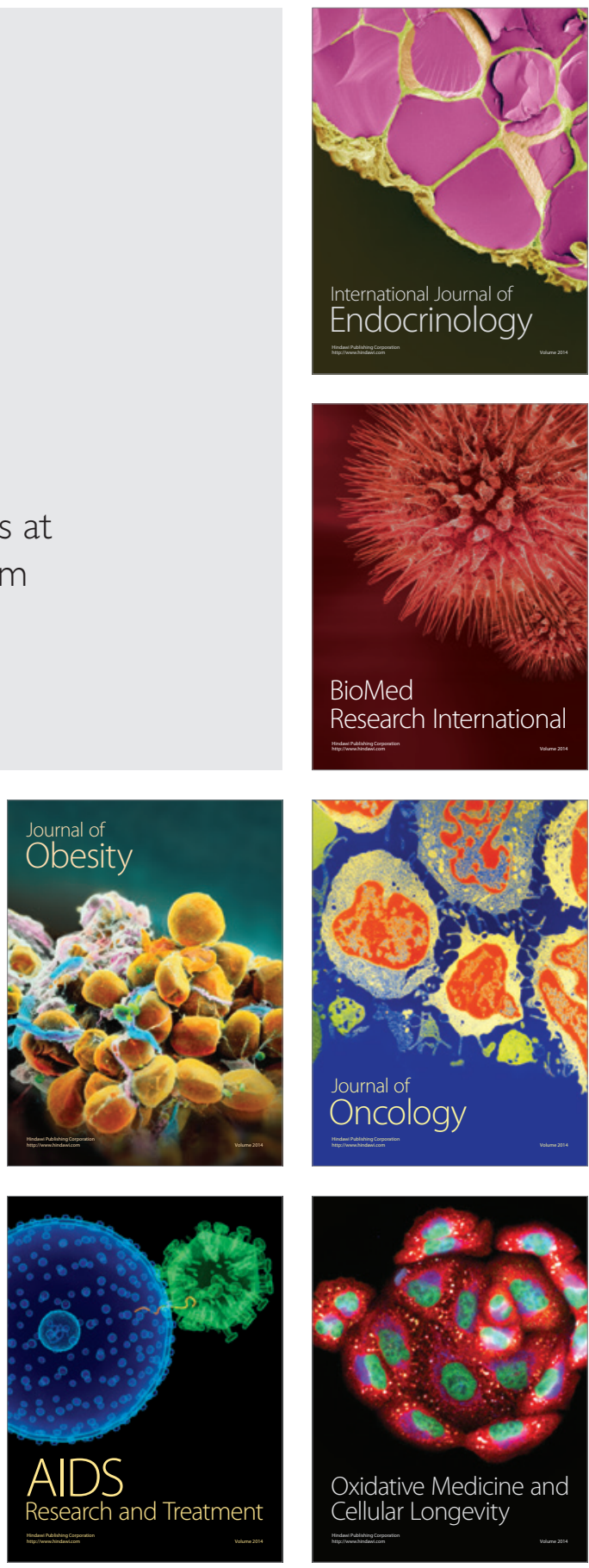